\title{
Sp1 sites in the mouse aprt gene promoter are required to prevent methylation of the CpG island
}

\author{
Donald Macleod, ${ }^{1}$ Jillian Charlton, ${ }^{1}$ John Mullins, ${ }^{2}$ and Adrian P. Bird ${ }^{1}$ \\ ${ }^{1}$ Institute of Cell and Molecular Biology, University of Edinburgh, Darwin Building, King's Buildings, Edinburgh EH9 3JR, \\ Scotland; ${ }^{2}$ Centre for Genome Research, Roger Land Building, King's Buildings, Edinburgh EH9 3JR, Scotland
}

\begin{abstract}
In an attempt to find the mechanism by which $\mathrm{CpG}$ islands remain free of methylation we have undertaken a detailed examination of the mouse adenine phosphoribosyltransferase (aprt) gene. This housekeeping gene has a CpG island that extends over the gene promoter and includes the first two exons. We show that the island is free of methylation at all $\mathrm{CpGs}$, whereas the flanks are methyated. Detailed patterns of methylation beyond the boundaries of the $\mathrm{CpG}$ island vary between cells. In vivo footprinting across the island region shows that three GC boxes clustered at the $5^{\prime}$ edge of the CpG island are occupied, most probably by Sp1. No other footprints are detected within the island region. Deletion or mutagenesis of the Sp1 sites causes de novo methylation of the CpG island in a transgenic mouse assay. Thus, the peripherally located Sp1 sites are necessary to keep the aprt island methylation free.
\end{abstract}

[Key Words: CpG islands; aprt; DNA methylation; in vivo footprinting; chromatin; LMPCR]

Received July 11, 1994; revised version accepted August 10, 1994.

CpG islands are DNA sequences that are on average $1 \mathrm{~kb}$ long and are found almost exclusively at the $5^{\prime}$ end of genes (Bird 1986, 1987). In mouse and man these genes include all sequenced housekeeping genes and many genes that show a tissue-restricted pattern of expression (Antequera and Bird 1993). CpG islands are expected to be nonmethylated when passed through the germ line, as methylation would subsequently lead to deamination and loss of the island structure (Cooper et al. 1983; Tykocinski and Max 1984; Bird et al. 1985). In somatic cells CpG islands are normally found to be nonmethylated, even in tissues where the gene is not expressed, but there are a few exceptions, including island-containing genes of the inactive $\mathrm{X}$ chromosome (for review, see Riggs and Pfeifer 1992), the testis-specific H2B gene of rat (Choi and Chae 1991), and several "imprinted" genes such as H19 (Ferguson-Smith et al. 1993) and Igf2r (Stöger et al. 1993). In all these cases, however, the CpG islands appear to be nonmethylated in the germ line (Driscoll and Migeon 1990; Choi and Chae 1991; Brandeis et al. 1993).

The CpG dinucleotide is the target for the mammalian methyltransferase that methylates the cytosine residue at the carbon 5 position. As CpG islands are rich in these dinucleotides, how do they remain free of methylation? Several models can be proposed, the simplest of which is that $\mathrm{CpG}$ islands are a poor substrate for the methyltransferase. In support of this idea, it has been shown that CpG-rich sequences are methylated relatively inefficiently in vitro (Carotti et al. 1989), suggesting that the high density of $\mathrm{CpG}$ dinucleotides in islands or their $\mathrm{G}+\mathrm{C}$ richness inhibits the methyltransferase. The weakness of this model is that it does not explain why CpG islands are methylated on the inactive $\mathrm{X}$, at imprinted genes, and also at nonessential genes in cultured cell lines (Antequera et al. 1990; Jones et al. 1990). A second model proposes that $\mathrm{CpG}$ islands are subject to de novo methylation but that the modification is removed by an island-specific demethylating activity (Frank et al. 1991). The model is based on the finding that partially methylated $\mathrm{CpG}$ islands lose methylation when introduced into fertilized mouse eggs or embryonic cells (Szyf et al. 1990; Frank et al. 1991). Demethylation may only occur when relatively few CpG sites within the transgene island are methylated but not when all CpGs are methylated (Choi and Chae 1993).

A third model proposes that steric hindrance by protein factors is responsible for excluding the methyltransferase from CpG islands (Bird 1986). Because CpG islands colocalize with gene promoters, transcription factors may be required for island protection. Evidence in favor of this model has come from in vivo footprinting studies of protein-DNA interactions within the CpG islands of the human PGK-1 gene (Pfeifer et al. 1990; Pfeifer and Riggs 1991) and the HTF9 locus (Stapleton et al. 1993). Multiple factors are bound over both of these CpG islands. In contrast, the methylated $P G K-1$ island of the inactive $\mathrm{X}$ chromosome has nucleosome-like structures replacing transcription factors (Pfeifer and Riggs 1991). These results suggest that in these cases, protein factors 
are bound across the island and could, in theory, block the methyltransferase by steric hindrance. Indirect support for the steric hindrance model has also been inferred from transgenic experiments showing that the CpG islands of transgenes can become methylated at high copy number, suggesting that there is a limited supply of factors that are capable of protecting the island (Mehtali et al. 1990; Gundersen et al. 1991). A limitation of the model is that it does not simply explain how inactive genes can nevertheless retain $\mathrm{CpG}$ islands that are methylation free. For example, the human $\alpha$-globin and retinol-binding protein genes are each expressed in only one tissue but have nonmethylated islands in all cell types that have been examined (Bird et al. 1987; Antequera et al. 1990).

In this study we have investigated the basis of immunity to methylation in a specific CpG island. We chose the mouse aprt gene as a test system, as this housekeeping gene has been studied previously (Dush et al. 1985, 1988), and its CpG island occupies a typical location, extending $\sim 600 \mathrm{bp}$ from the promoter downstream into the transcribed region. The bidirectional HTF9 promoter and the $P G K$ promoter are both atypical in this respect, as the promoter region is centrally located within the island in each case. We have carried out a detailed analysis of methylation at all CpGs across the island and have identified regions that are bound to proteins in vivo. To test the significance of bound factors we have deleted and mutated the binding sites. Both treatments abolish the protection of the $\mathrm{CpG}$ island region against DNA methylation. Thus, the binding sites are important, but their asymmetrical location within the island suggests that protection against the methyltransferase is not simply attributable to steric hindrance.

\section{Results}

DNA methylation analysis of the aprt $C p G$ island

To accurately position the $\mathrm{CpG}$ island relative to the structure of the mouse aprt gene, the distribution of the CpG dinucleotides was plotted using the published DNA sequence (Fig. 1A; Dush et al. 1985). The greatest concentration of $\mathrm{CpGs}$ extends from the promoter at the left edge over the first two exons into the second intron of the gene. To analyze the boundaries of the island with respect to methylation, the bisulfite-modification technique was used (Frommer et al. 1992). This procedure changes nonmethylated cytosines into uracils while leaving methylated cytosines unchanged. Subsequent PCR amplification and sequencing reveals the methylated bases. Unlike the genomic sequencing method, which examines the combined pattern of methylation of a large number of molecules simultaneously, this method allows the sequence of individual molecules to be resolved. A large region of the aprt gene $(1936 \mathrm{bp})$, including the whole CpG island, was analyzed in this way using liver DNA as starting material. These results show the position of methylated CpG sites in four independent clones, each corresponding to the sequence of the gene within an individual liver cell (Fig. 1B). In each case it can be seen that the central region, which also shows the highest frequency of CpGs, is completely nonmethylated. The analysis also shows which sites in the flanking DNA are methylated and allows the boundaries of the $\mathrm{CpG}$ island to be determined in terms of both CpG frequency and methylation. The methylation-free region extends from position 610 to 1425 , and this coincides with the region of elevated $\mathrm{CpG}$. In the flanking region it is notable that individual sites are methylated in some molecules and nonmethylated in others. Thus, although the overall pattern of methylation is inherited /Holliday and Pugh 1975; Riggs 1975/ methylation of individual sites is not clonally derived.

\section{In vivo footprinting across the aprt $C p G$ island}

Having established the detailed methylation pattern, we next asked whether protein factors were bound within
A

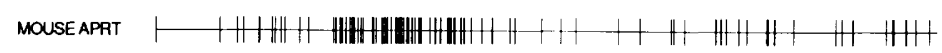

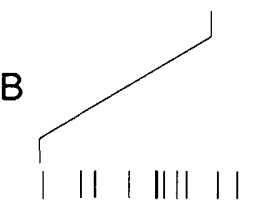

$\circ \bullet \circ \bullet \bullet \bullet$

- 0 - $\bullet$

$\circ \quad 0 \bullet \circ \infty \infty \circ 0$

$\circ \bullet \bullet \quad 0 \quad \infty \quad 00$ $\Delta \square \sqrt{\square} \square$

1000
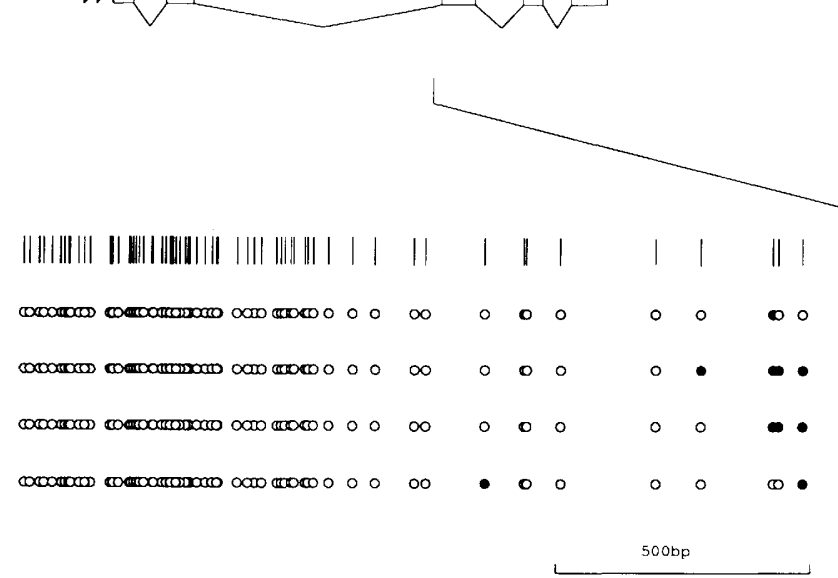

Figure 1. (A) A CpG plot of the mouse aprt gene. Each vertical line indicates the position of each CpG dinucleotide in the DNA sequence (Dush et al. 1985). The positions of exons are indicated by open rectangles and transcription start sites by open arrowheads (Dush et al. 1988). The scale (top) is in base pairs. (B) An enlarged plot of a section of the above CpG plot, showing the part of the APRT sequence used in the methylation analysis. The series of vertical lines indicates the position of each CpG dinucleotide, and underneath this, the open circles indicate whether the cytosine in the dinucleotide is nonmethylated $(O)$ or methylated (O). Each horizontal line of circles represents the methylation analysis from one of four independent clones. 
the CpG island. To detect protein-DNA interactions in vivo we used the ligation-mediated polymerase chain reaction (LMPCR) technique (Mueller and Wold 1989) to study the aprt promoter in $\mathrm{F} 9$ embryonal carcinoma (EC) cells. We designed pairs of DNA primers for LMPCR that spanned the island sequence (see Fig. 2A). By comparing the aprt "G ladder" produced by dimethylsulfate (DMS) piperidine cleavage of naked DNA with that from DMStreated F9 cells, we could establish sites of protein-DNA interaction. Unlike DNase I footprinting in vitro, where protein binding is shown as large gaps in the DNase I ladder, footprints using DMS are more subtle and are identified by missing or hypersensitive guanosine bases in the DNA from DMS-treated cells. Three footprints were obtained (Fig. 2B), which coincided with the three GC boxes identified in the aprt promoter (Dush et al. 1985). The GC box is the consensus binding site for the ubiquitous transcription factor Spl (Kadonaga et al. 1986). In the mouse aprt gene these sites have been shown previously to bind purified Spl by DNase I footprinting in vitro and are sufficient for transcription of the gene (Dush et al. 1988). Aside from the Spl sites, no
Figure 2. In vivo footprinting of bound factors. (A) A schematic diagram showing regions that were analyzed by $L M P C R$. (Top) The position of the CpG dinucleotides as in Fig. 1. The position of overlapping primer pairs used for in vivo footprinting are indicated relative to the $\mathrm{CpG}$ plot above, by a dot and number at the end of the arrowed lines. The length of the arrowed line corresponds to the region analyzed with each primer set; arrows pointing to the left are primers complementary to the lower strand of the sequence, arrows to the right are primers complementary to the upper strand. The positions of the three GC boxes are indicated by three thick vertical lines under the CpG plot. The positions of methylation-sensitive restriction enzyme cleavage sites within the CpG island are indicated: (H) HpaII; (S) Smal. The bracketed region under the CpG plot shows the position of the BsaBIMaeII fragment (see text). The scale at the top is in base pairs. $(B)$ Results of in vivo footprinting reactions obtained using primer sets 4 (lanes $1-3$ ) and Xl, (lanes 4-6). LMPCR reactions were run on standard sequencing gels, electroblotted, and hybridized to an aprt PCR probe (primers 1-X1, see $A$ |. Each lane shows the G ladder obtained from DMS-treated purified F9 DNA (lanes 1,4 ) or from F9 cells treated with DMS for 2 min (lanes 2,5) or $5 \mathrm{~min}$ (lanes 3,6). Brackets show the positions of GC boxes (I, II, and III) that correspond to the DNA sequences below. Small circles show the position of weak or absent $G$ bands (O) or hyper-reactive $G$ bands (O). Arrows A and B show the position of transcription start sites relative to the GC boxes as mapped by Dush et al. (1988). Footprints are detected at each of the three GC boxes, on both strands of the DNA, and were confirmed by repeating the reactions several times. (C) Results of footprinting reactions with two primer sets, 5 and 8 . Lanes 1 and 4 are LMPCR amplifications of purified F9 DNA after DMS/ piperidine cleavage. LMPCR amplifications of DMS-treated F9 cells for $2 \mathrm{~min}$ (lanes 2,5) or $5 \mathrm{~min}(\operatorname{lanes} 3,6)$. Although some variation in band intensity can be detected in these gels, it was not reproducible (repeated twice) and no footprints were identified using these primer sets.

\section{A}

MOUSE APRT

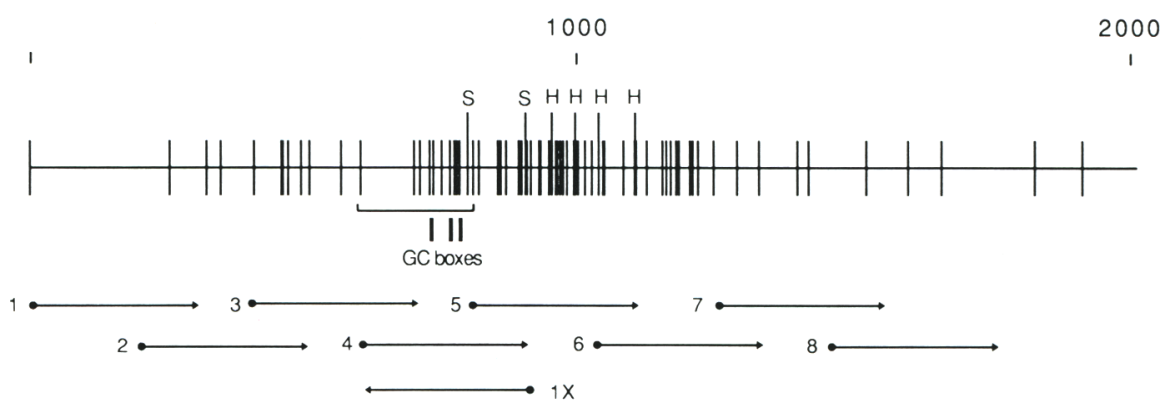

B

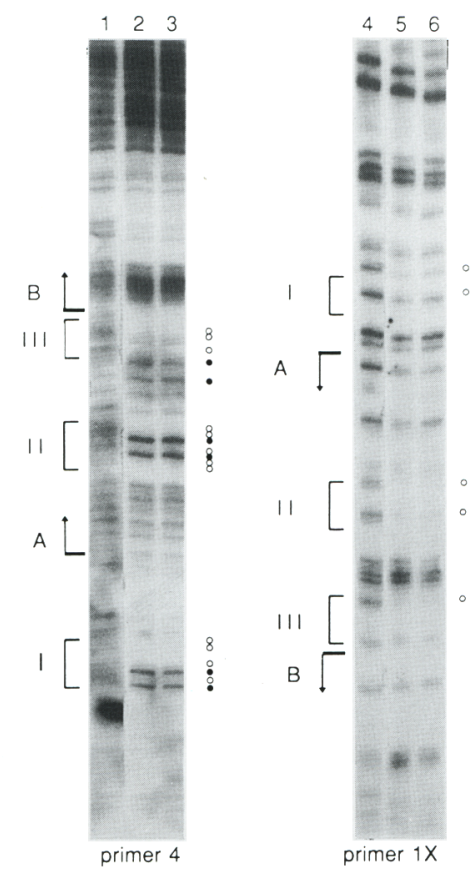

Sp1 binding sites

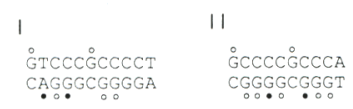

III

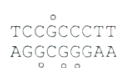

C

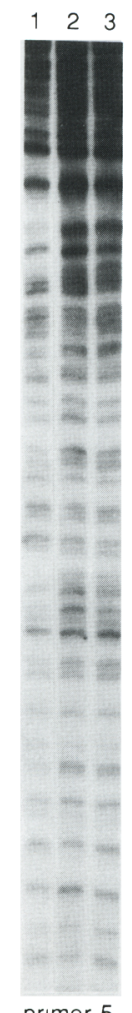

456

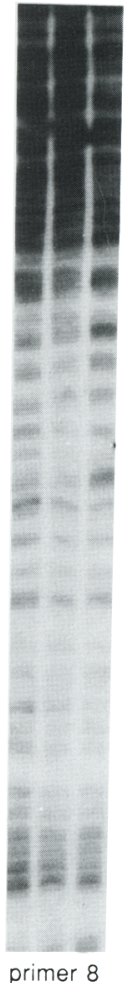


other factor binding sites have been identified within the promoter (Dush et al. 1988) and there is no TATA box (Dush et al. 1985). In our analysis, no other footprints could be identified using the other primer sets (e.g., Fig. $2 \mathrm{C}$. These results suggest that protein factors are not bound over the entire island but only within the promoter that is at its left-hand edge (see Fig. 2A).

\section{Nucleosome-like structures are positioned over the $C p G$ island}

Transcription factors are not the only proteins expected to bind CpG island DNA, as nucleosomes are also likely to be present. To determine nucleosome position, $\mathrm{F} 9 \mathrm{nu}$ clei were incubated with micrococcal nuclease, which cleaves between nucleosomes. Sites cut by the enzyme in the aprt gene were detected by LMPCR using three primer sets spanning the CpG island region (primers 1 , $\mathrm{X} 1$, and 7; Fig. 3B). Micrococcal nuclease cleavage sites were clustered in the region that includes the three occupied GC boxes and transcription start sites (Fig. 3A). The same region is also hypersensitive to cleavage by DNase I and endogenous nucleases (data not shown). In addition to these cleavage sites, micrococcal nuclease cuts at $\sim 200$-bp intervals across the $\mathrm{CpG}$ island (primer 1, Fig. 3A). At the boundaries of the island, cleavage sites

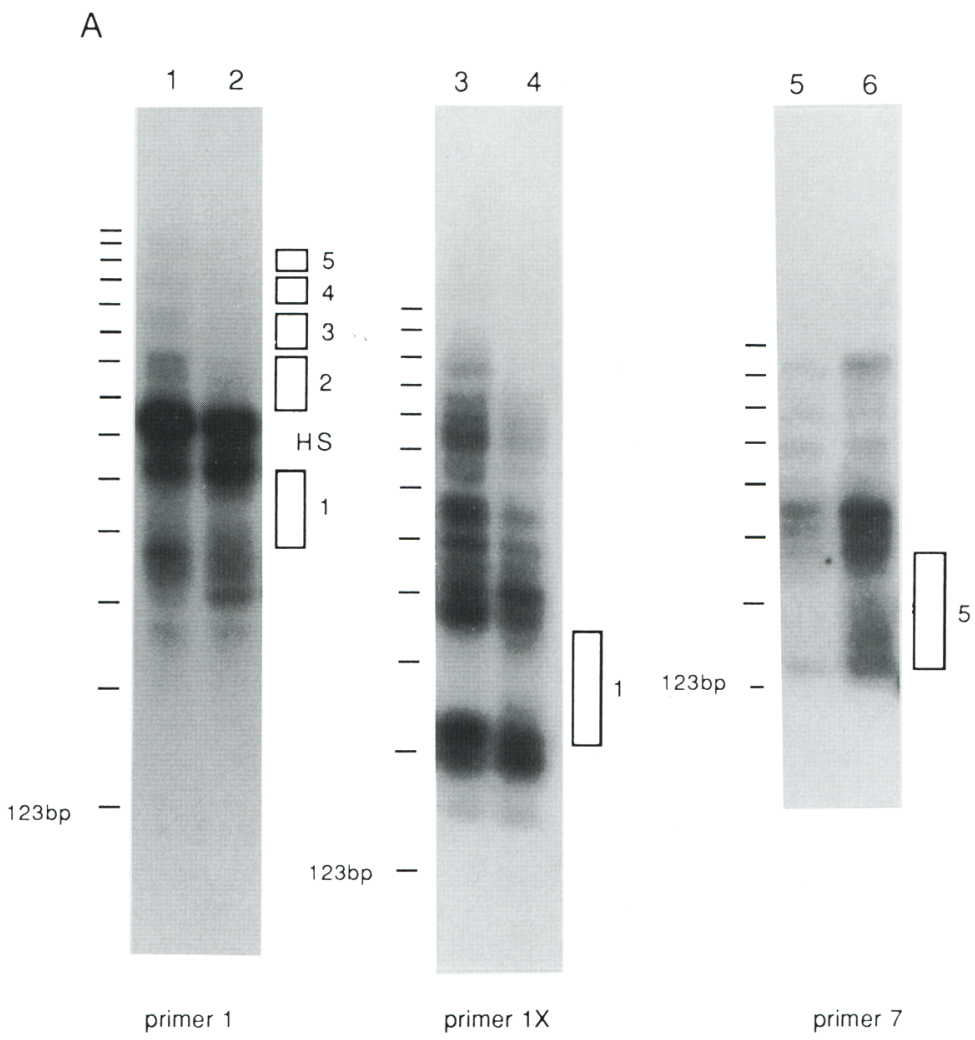

B

Mouse adenine phosporibosyltransferase (APRT) gene

$$
1000
$$
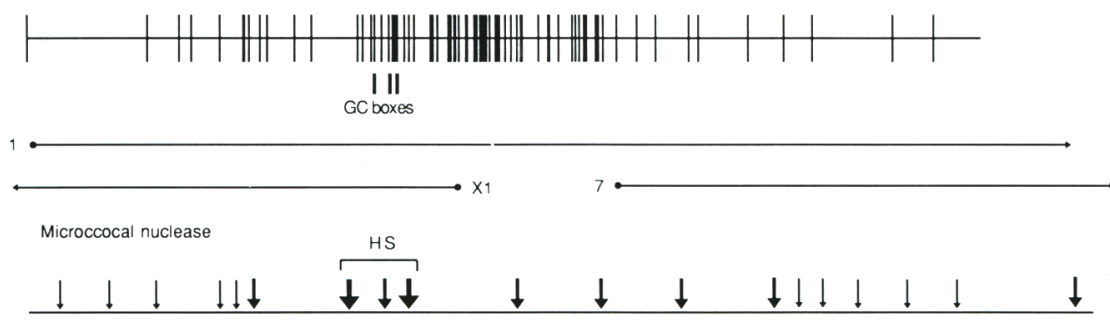

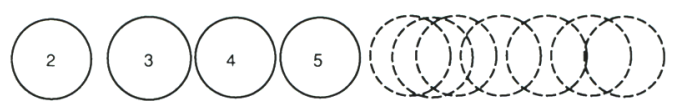

Figure 3. In vivo footprinting of nucleosomes. (A) Results of in vivo footprinting of nucleosomes using LMPCR amplification of DNA obtained from F9 nuclei restricted with micrococcal nuclease. The products were electrophoresed on $2 \%$ agarose gels, blotted to nylon membranes, and hybridized to an aprt probe /for primer sets 1 and X1, a PCR probe corresponding to position 45-883 of the aprt sequence was used and for primer set 7, a PCR probe between 1265 and 1502 was used). Each pair of tracks shows LMPCR products from nuclei digested with 0.16 units of enzyme (lanes $1,3,5$ ) or 0.32 units (lanes $2,4,6$ ). The primer sets used are indicated underneath. The open vertical rectangles represent protected regions and their position, relative to the CpG plot, is shown in $B$. The ladder of horizontal bands alongside the autoradiographs shows the position of 123-bp marker bands (BRL). (HS) Nuclease hypersensitive region from our experiments. $(B)$ The CpG plot of the aprt gene as described in Fig. 2. As in Figure 2A, the positions of the primers used to amplify micrococcal nuclease-cleaved DNA are indicated by a dot on the numbered, arrowed line under the CpG plot. The length of the arrowed line corresponds to the region analyzed with each primer set; arrows pointing to the left are primers complementary to the lower strand of the sequence, arrows to the right are primers complementary to the upper strand. The sites cleaved by the enzyme relative to the $\mathrm{CpG}$ plot are indicated by vertical arrows below. The arrow size is an approximate indication of the strength of signal obtained by hybridization to the probe as determined from $A$. The numbered circles represent the protected regions (which we suggest are nucleosomes). (HS) The micrococcal nuclease/DNase I hypersensitive site. 
are weak and irregularly spaced (primers $\mathrm{Xl}$ and 7, Fig. $3 \mathrm{~A})$. The size of the regions that are protected from the nuclease implies that they correspond to nucleosomes that are uniquely positioned across the island (Fig. 3B). The absence of a regular pattern of protection outside the island suggests that nucleosomes in the flanks are positioned differently in different cells.

\section{Deletion of the aprt promoter leads to methylation of the CpG island}

The occupied GC boxes are at the left edge of the CpG island (Fig. 2A). To determine whether Spl binding in this region alone could protect the whole island from methylation, we tested the consequences of deleting or mutating the promoter region. To assay methylation, transgenic mice were generated by the injection of DNA constructs into the male pronucleus of fertilized mouse eggs, which were then inserted into the uterus of pseudopregnant mice. The transgenic offspring were subsequently identified by analysis of tail DNA. The control construct for injection comprised a 3.4-kb BglII-SphI fragment, pABS, containing the unaltered aprt island that had been subcloned from the genomic aprt clone pSAM 6.3 (Turker et al. 1991). A deletion (pADB) was made by removing a $210-$ bp BsaBI-MaeIl fragment that includes the transcriptional start sites and GC boxes from pABS (see Fig. 4). Each of the constructs was digested with EcoRI and SphI, which removed all prokaryotic DNA sequence, except for a short region of polylinker containing a KpnI site. These constructs were purified and used to produce transgenic mice. Analysis of tail DNA from founder animals was then carried out by Southern blotting to determine the methylation status of the transgenes. In each case, this was facilitated by the presence of the KpnI site within the polylinker at the 5' end of the transgene (see Fig. 5A). Transgenes could be distinguished from the endogenous gene, as they gave a $1.7-\mathrm{kb}$ restriction fragment (pABS) and a $1.5-\mathrm{kb}$ fragment $(\mathrm{pA} \Delta \mathrm{B})$ compared with the $5-\mathrm{kb}$ fragment derived from the endogenous gene in KpnI digests. Methylation was assayed at several sites within the island using the methylation-sensitive restriction enzymes $S m a I$ and $H p a I I$ (see Fig. 2A). If the SmaI site was nonmethylated, a KpnI-SmaI double digest produced a transgene-specific $1.1-\mathrm{kb}$ restriction fragment with $\mathrm{pABS}$ and $\mathrm{pA} \triangle \mathrm{B}$. The $2.5-\mathrm{kb}$ fragment produced from the endogenous gene served as an internal control for complete digestion. Fur-

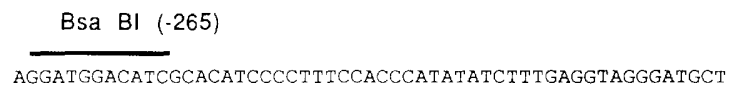

TGTGTTTAGGCAGCTCAAGAAATCTAACCCCTGACTCAGGCCCCACACACACCTC

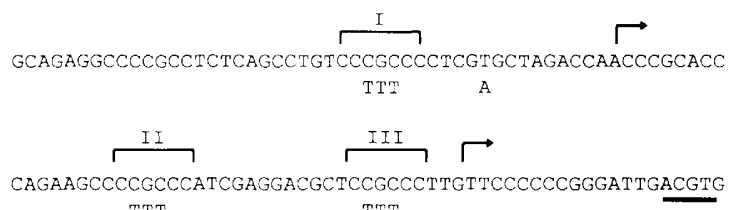

T'T T

TrT

Mae $\|(-55)$

Figure 4. DNA sequence that was deleted $(\mathrm{pA} \Delta \mathrm{B})$ or mutagenized (pAZM2) from the wild-type aprt clone (pABS). Part of the aprt sequence from the aprt promoter is shown (Dush et al. 1985). The arrows indicate the position of the transcription start sites. The positions of the BsaBI and MaeII sites are indicated. These enzymes were used to cut this fragment $(210 \mathrm{bp}$ ) from the wild-type parent clone, pABS, to obtain $\mathrm{pA} \triangle \mathrm{B}$. The deletion removes the three GC boxes and transcription start sites. The GC boxes are bracketed and labeled (I,II, and III). The base changes in each box (CGC $\rightarrow$ TTT) to create clone pAZM2 from the parent clone pABS are shown underneath. A single $\mathrm{T} \rightarrow \mathrm{A}$ change, which creates an XhoI site, was used for screening purposes (see Materials and methods).

ther sites were tested by KpnI-HpaII digestion, which provided additional information on the level of methylation at other sites within the CpG island (Figs. 2A and $5 \mathrm{~A})$.

In an analysis of 10 founder mice with the wild-type construct pABS, (Fig. 5B) all but one were free of methylation at the SmaI site, as the $1.7-\mathrm{kb} K p n I$ restriction fragment was abolished completely by this enzyme. These transgenes were also nonmethylated at many, if not all, HpaII sites (Fig. 5B). Thus, the nonmethylated $\mathrm{CpG}$ island is recreated at the aprt transgene in nearly all of the founder animals. Eleven $\mathrm{pA} \Delta \mathrm{B}$ founder mice were also tested in the same manner (Fig. 5C). Unlike the controls, the SmaI site was heavily methylated in these transgenes, as the $1.5-\mathrm{kb}$ restriction fragment is largely resistant to cleavage, and very little of the $1.1-\mathrm{kb}$ transgene-specific fragment, which would be expected if this site were nonmethylated, is seen. The Hpall sites were also heavily methylated, as most of the transgene-specific $1.5-\mathrm{kb} \mathrm{KpnI}$ fragment is uncut by this enzyme. The

Figure 5. Methylation analysis of transgenic founder mice using methylation-sensitive restriction enzymes. $(A)$ Restriction enzyme map of the endogenous genomic aprt gene and transgenes. Each vertical line on the map shows the position of KpnI (K), SmaI (S), BglII (B), SphI (P), and HpaII (H) sites. One of the HpaII sites (outside the CpG island), indicated by an asterisk $\left({ }^{*}\right)$, is partially methylated in the genome (see Turker et al. 1989). The solid horizontal bar represents the position of the probe used to hybridize to the Southern blots. The $\mathrm{CpG}$ island is denoted by brackets. $(B)$ A Southern blot obtained from tail DNA of wild-type $(+)$ or pABS transgenic mice (T1-T4) hybridized to an aprt-specific probe (see A). DNA was restricted with KpnI (lanes 1,4,7,10,13), KpnI + SmaI (lanes 2,5,8,11,14), or KpnI + HpaII (lanes 3,6,9 12,15). (M) Radioactively labeled 1-kb marker (BRL); the sizes of some hybridizing restriction fragments are shown in the margin (in bp). The arrowed $\mathrm{T}$ shows the position of the transgene-specific restriction fragment in the KpnI digests. $(C)$ As above, but with four pA $\Delta \mathrm{B}$ transgenic mice. DNA was restricted with $K p n I$ (lanes $1,4,7,10), K p n I+S m a I(1$ anes $2,5,8,11)$, or $K p n I+H p a I I(l a n e s 3,6,9,12)$. (D) As above, but with four pAZM2 transgenic mice. DNA was restricted with KpnI $($ lanes $1,4,7,10)$, KpnI + SmaI (lanes 2,5,8,11), or KpnI + HpaII (lanes 3,6,9,12). 
degree of methylation varied between founder animals, but the transgenes were all shown to be highly methyl-

A

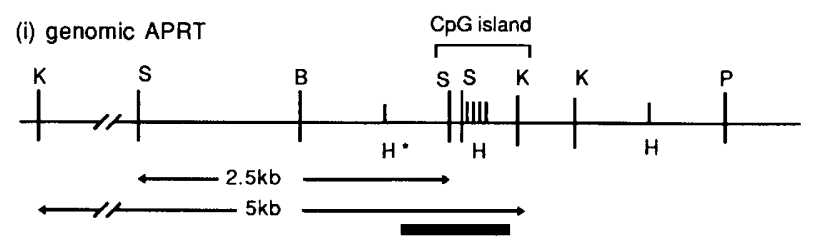

(ii) pABS / pAZM2

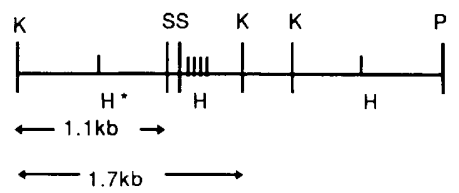

(iii) $\mathrm{pA} \triangle \mathrm{B}$

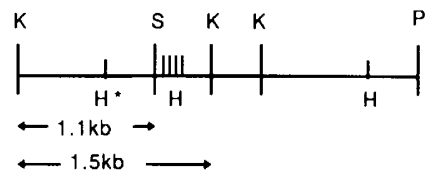

C

$\mathrm{pA} \triangle \mathrm{B}$ transgenics

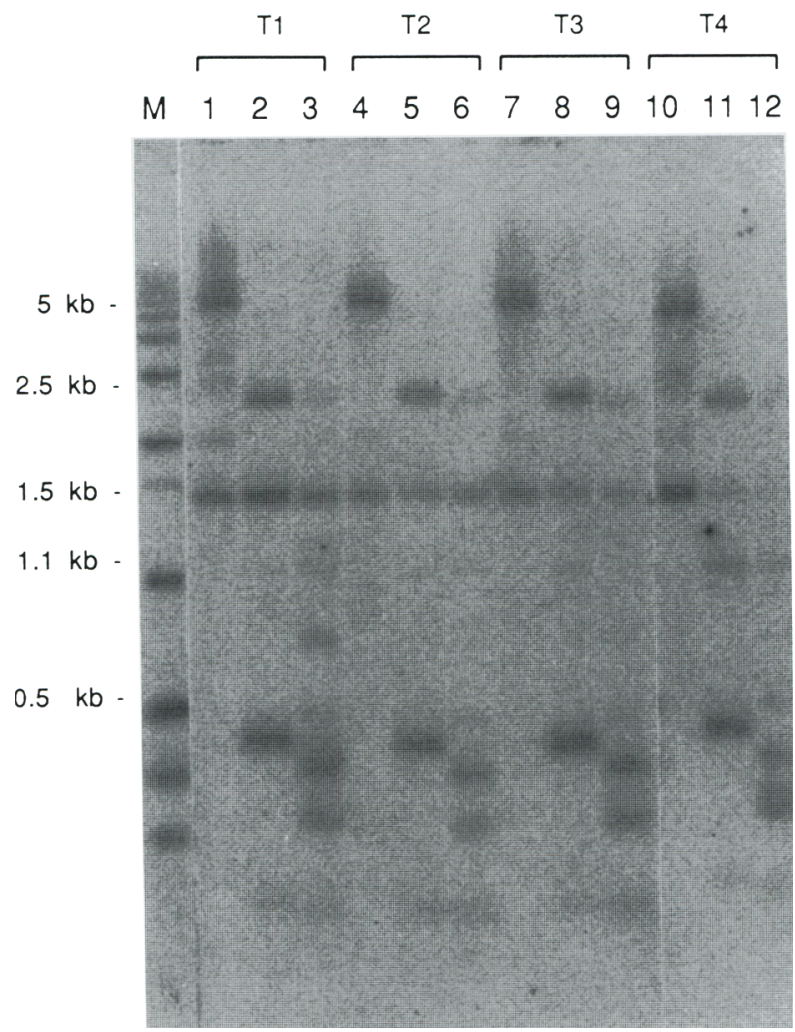

ated except in 1 of 11 examples, where the level of methylation was low (Fig. 5C).

B

pABS transgenics

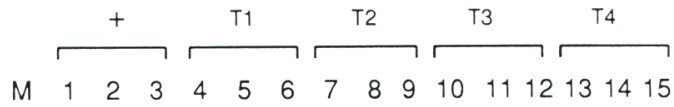

$5 \mathrm{~kb}$

$2.5 \mathrm{~kb}-$

$1.7 \mathrm{~kb}$

$1.1 \mathrm{~kb}$.

$0.5 \mathrm{~kb}$

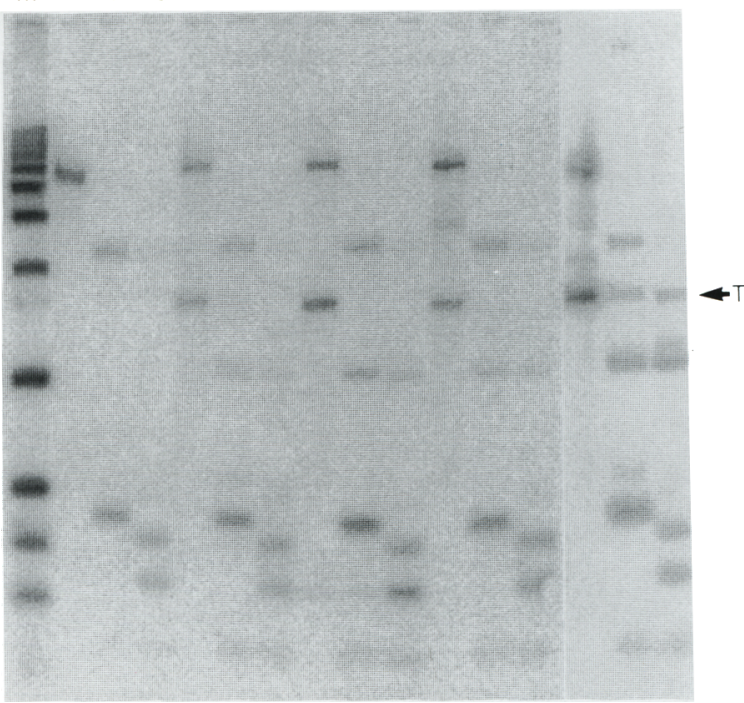

D

pAZM2 transgenics

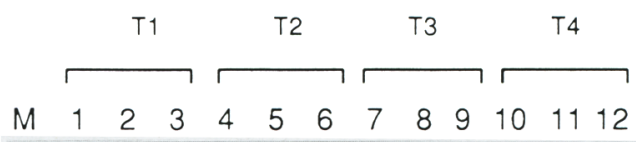

$5 \mathrm{~kb}$

$2.5 \mathrm{~kb}$

$1.7 \mathrm{~kb}$

$1.1 \mathrm{~kb}$

$0.5 \mathrm{~kb}$.

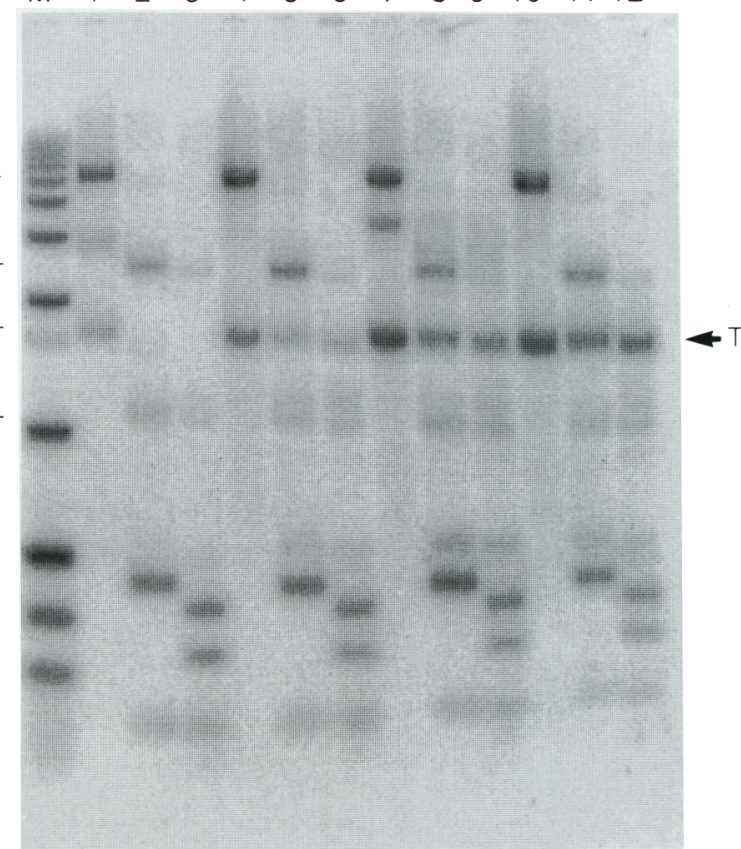

Figure 5. (See facing page for legend.) 
(A)

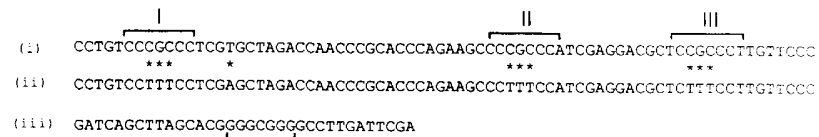

(B)

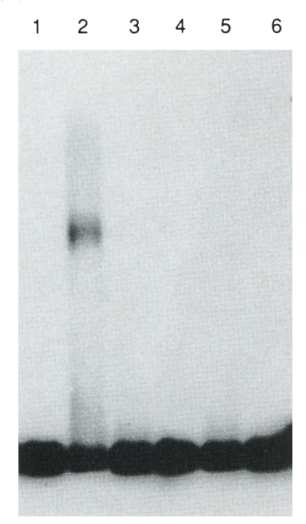

(C)

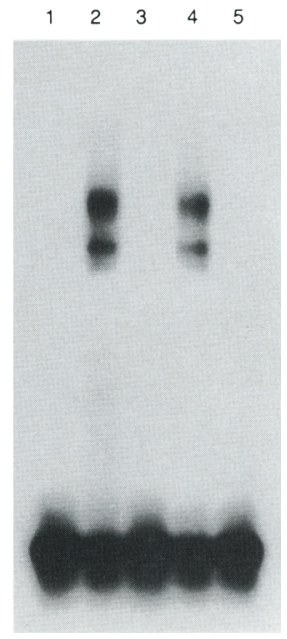

Figure 6. Bandshift experiment showing interaction with aprt probes and F9 protein extract. $(A)$ (i) The wild type (N1) oligomer sequence of aprt gene contained in pABS. The brackets mark the position of the GC boxes. (ii) The mutated (M1) oligomer sequence showing bases that are changed $\left({ }^{*}\right)$ from the above. This sequence is contained in pAZM2. (iii) The sequence of the high affinity Spl consensus binding site, showing the position of the GC box. ( $B)$ Autoradiograph showing the bandshifts obtained using a 210-bp probe (the same fragment as shown in Fig. 4), which includes the three GC boxes. Bandshift reactions using the wild-type aprt sequence (from pABS) are shown in lanes 1-3. Lanes 4-6 show bandshift reactions using the same sized probe from the mutated clone, pAZM2. Reactions in lanes 1 and 4 contained no extract. Reactions in lanes 2, 3, 5, and 6 contained $5 \mu \mathrm{g}$ of F9 protein extract. Reactions in lanes 3 and 6 have been preincubated with $0.1 \mu \mathrm{g}$ of $\mathrm{Spl}$ double-stranded oligomer [sequence (iii) above]. Unbound probe accounts for the radioactivity at the bottom of the gel; a specific complex is only seen in lane 2. (C) Autoradiograph showing the bandshifts obtained using the Sp1 oligomer [sequence (iii) above). (Lane 1 No extract; (lanes 2-5) $5 \mu \mathrm{g}$ of F9 protein extract. Reactions in lanes 3, 4, and 5 are competed with $0.1 \mu \mathrm{g}$ of $\mathrm{N} 1$ [sequence (i) above] M1 [sequence (ii) above], or Sp1 [sequence (iii) above], respectively. Unbound probe accounts for the radioactive band at the bottom of the gel. A specific complex is only seen in lanes 2 and 4 .

\section{Mutagenesis of the aprt Sp1-binding sites results in methylation of the $\mathrm{Cp} G$ island}

The above result showed that the 210-bp fragment from the aprt promoter was required to prevent methylation of the $\mathrm{CpG}$ island. As this region contains the entire promoter, the transcription start sites, and also includes part of the CpG island (see Fig. 2A), we tested whether the Spl sites themselves were important. Specific mutations were introduced simultaneously into the three GC boxes by in vitro mutagenesis to produce the pAZM2

construct (see Fig. 4). To test whether mutagenesis of these sites occluded Spl binding, a 210-bp fragment containing the intact sites (pABS) or the mutated sites (pAZM2) was end-labeled and incubated with a crude protein extract from F9 cells. Protein-DNA interaction was shown by bandshift (Fig. 6). The pABS fragment formed a complex with the extract that was effectively competed out by a double-stranded oligomer containing a high affinity binding site for Sp1 (see Fig. 6B, lanes 2,3). This confirmed that $\mathrm{Spl}$ bound to this fragment. No other factors besides Spl interact with the probe to produce a complex. The pAZM2 fragment, in which the Spl-binding sites have been mutated (see Fig. 4A), does not form a complex (Fig. 6B, lane 5). In a reciprocal experiment (Fig. 6C) a DNA duplex containing a high affinity binding site for Spl was used in competition with a double-stranded wild-type aprt oligomer (N1) or an oligomer carrying mutations in the GC boxes (M1) (see Fig. 6A). The results of the bandshifts clearly show that only the wild-type oligomer effectively competes with the high affinity site for Spl (Fig. 6C, lane 3). The mutant M1 oligonucleotide is unable to compete (Fig. 6C, lane 4).

The EcoRI-SphI fragment was purified from the pAZM2 clone and used to produce transgenic mice. The results of the methylation analysis on four of the founder animals is shown in Figure 5D. As with pA $\Delta \mathrm{B}$, the transgenes are highly methylated in four of five founder animals tested as the 1.7-kb KpnI fragment is largely resistant to digestion with SmaI and HpaII (Fig. 5D). The transgene was nonmethylated in the fifth animal. This analysis shows that $\mathrm{Spl}$ sites are required to ensure that the aprt gene remains methylation free.

\section{Discussion}

We have shown that Spl elements play an important part in the maintenance of the aprt CpG island. Transgene constructs in which the GC boxes in the aprt promoter have been deleted or mutated no longer bind Spl and no longer exclude methylation from the $\mathrm{CpG}$ island (Table 1). It has been suggested previously that factors may be required to protect CpG islands (Bird 1986) and also that Spl may be involved (Höller et al. 1988). Our data provide direct evidence for this view. Previous attempts to define the origin of methylation-free islands have not implicated factor binding, but with hindsight

Table 1. Summary of the methylation results from transgenic mice generated with the three DNA constructs $p A B S, p A \Delta B$, and $p A Z M 2$

\begin{tabular}{lcc}
\hline & Methylated & Nonmethylated \\
\hline pABS & $(1)$ & 9 \\
pA $\triangle B$ & 10 & 1 \\
pAZM2 & 4 & 1 \\
\hline
\end{tabular}

The numbers refer to the number of founder animals tested. Parentheses indicate weakly methylated. 
the results that were obtained are compatible with the conclusions drawn here. Szyf et al. (1990) identified a 214-bp fragment from the mouse Thy-1 gene promoter that contained a "portable signal," which protected the Thy-1 gene (and plasmid vector) from methylation after transfection into embryonic stem (ES) cells. It was shown later that this DNA fragment contains binding sites for transcription factors, including Spl (Spanopoulou et al. 1991). Mummaneni et al. (1993) proposed that the boundaries of $\mathrm{CpG}$ islands have sequences that block the spread of methylation from nearby methylation centers. The existence of methylation centers was inferred from the finding that a $\mathrm{CpG}$ island fragment from the aprt gene became methylated when placed upstream of its normal position following transfection into EC cells. The interpretation was that the island was unable to resist the influence of a methylation center when placed close to it. We note, however, that the CpG island fragment that was translocated omits two of the three GC boxes. Based on the work presented here, it seems likely that the loss of these sites may have been sufficient to lead to de novo methylation of the island wherever it was placed. Thus, these results are consistent with the proposal that binding sites for a group of factors, which may or may not always include $\mathrm{Spl}$, are required for protection of $\mathrm{CpG}$ islands from methylation. It has been noted previously that GC boxes are frequently found within $\mathrm{CpG}$ islands (Gardiner-Garden and Frommer 1987).

It is surprising that occupied Spl sites at one edge of the aprt CpG island are capable of preventing methylation of CpG sites some distance downstream. That these are the only occupied sites for sequence-specific binding proteins in the island is suggested by the absense of additional footprints in vivo and the presence of typically spaced nucleosomes across the island. The DNase $\mathrm{I} /$ micrococcal nuclease hypersensitive site is also located at the island periphery, coincident with the Spl sites and the transcription start sites. In the great majority of cases, $\mathrm{CpG}$ islands extend downstream from the promoter of a gene into its transcription unit. Thus, it may be generally true that bound transcription factors mark the $5^{\prime}$ boundary of an island, the methylation-free domain extending several hundred base pairs downstream from this point. How factor binding prevents methylation and why the nonmethylated domain is relatively constant in length are unanswered questions at present.

Their asymmetrical location makes it unlikely that the $\mathrm{Spl}$ sites exclude methylation by sterically preventing access by the methyltransferase. If this were the case, the methylation-free region would be expected to straddle the bound factors symmetrically. As shown previously (Tazi and Bird 1990), CpG islands are generally highly accessible to proteins (nucleases) and have features of "open chromatin" such as hyperacetylated histones and depletion of histone H1. It is difficult to sustain the argument that such an open structure should be much less accessible to the methyltransferase than typical nucleosomal chromatin. It is more likely that the binding of factors to the island excludes DNA methylation by a mechanism other than steric hindrance.

It may be significant that the presence of $\mathrm{Spl}$ is also required to drive transcription of the aprt promoter (Dush et al. 1988). Thus, changes that abolish promoter activity also abolish the ability of the island to remain free of methylation. The relationship between transcription and lack of $\mathrm{CpG}$ island methylation, however, remains a puzzle. Many genes with $\mathrm{CpG}$ islands, such as the human $\alpha$-globin gene, are highly tissue specific in expression yet are nonmethylated in expressing and nonexpressing tissues alike (Bird et al. 1987). A possible explanation is that genes of this kind are poised for transcription but do not, for some reason, make stable RNA. We have investigated this possibility for the human $\alpha$-globin gene and the mouse myoD1 gene by assaying for run-on transcription in isolated nuclei of nonexpressing cells and have failed to detect any inappropriate transcription (F. Antequera and D. Macleod, unpubl.). The results confirm similar findings for the tissue-specific Thy-1 gene, which also has a CpG island (Kolsto et al. 1986). In addition, the results agree with evidence that neither the myoD1 gene (Mueller and Wold 1989) nor the $\alpha$-globin gene (Yagi and Groudine 1986) display open chromatin or DNase I hypersensitive sites in nonexpressing tissues. Thus, CpG islands can be maintained methylation free in the apparent absence of either transcription or an open chromatin configuration. An alternative possibility is that there is a stage in early embryos where all island-associated genes, including tissue-specific genes, are transcribed or transcriptionally competent. Lack of methylation could be established at this time and be replicated because of maintenance methylation in somatic cells, where transcription no longer occurs. Future experiments are designed to test this and other possibilities.

\section{Materials and methods}

Bisulfite modification and sequencing of genomic DNA

This procedure was essentially as described by Frommer et al. (1992). Mouse liver DNA (10 $\mu$ g) was first cleaved with EcoRI and then denatured in $0.2 \mathrm{M} \mathrm{NaOH}$ for $10 \mathrm{~min}$ at $27^{\circ} \mathrm{C}$ in a volume of $110 \mu \mathrm{l}$. The reaction was neutralized with $44 \mu \mathrm{l}$ of 5 $\mathrm{M}$ ammonium acetate and precipitated with $620 \mu \mathrm{l}$ of ethanol. The pellet was washed with $70 \%$ ethanol, air-dried, and resuspended in $100 \mu \mathrm{l}$ of cold sterile distilled water on ice, and 1.04 $\mathrm{ml}$ of fresh $3.8 \mathrm{M}$ sodium bisulfite and $60 \mu \mathrm{l}$ of $10 \mathrm{mM}$ Quinol were added. This mixture was overlayed with $200 \mu$ l of mineral oil and incubated at $50^{\circ} \mathrm{C}$ in the dark for $16 \mathrm{hr}$. The DNA was desalted and concentrated using Geneclean (Biol01), ethanol precipitated, and resuspended in sterile water. Aliquots were stored at $-20^{\circ} \mathrm{C}$. An aliquot of DNA was amplified using the modified primers CTGAATTCACCCTCTCCTTTAATAAAACAT and TAGAATTCAACCCAAATACTATACTAAA, which are derived from the aprt sequence at positions 70-91 and 23902414 (Dush et al. 1985) and then reamplified using the internal set, TTGAATTCTTTTGGGTGGTGTAAATTTGATTT and TTGAATTCTTGAGGGGTATGGGAATTTAGAGGTTAA at positions 191-210 and 2101-2128. PCR reactions were carried out in Thesit buffer (Ponce and Micol 1992). The resulting PCR 
fragments, containing EcoRI ends, were cloned into pBluescribe vector (Stratagene) and sequenced using Sequenase (U.S. Biochemical).

\section{In vivo footprinting using DMS}

DMS treatment of F9 DNA or whole cells and subsequent cleavage by piperidine, ligation of linkers, and LMPCR reactions were as described (Pfeifer et al. 1989) except for the following modifications. PCR reactions were in Thesit buffer (Ponce and Micol 1992; $30 \mathrm{~mm}$ tricine at pH 8.4, $2 \mathrm{~mm} \mathrm{MgCl}_{2}, 50 \mathrm{~mm}$ $\beta$-mercaptoethanol, $0.1 \%$ gelatin, $0.1 \%$ Thesit) with the addition of $10 \%$ DMSO. In some reactions, $1 \mu \mathrm{g}$ of single strandedbinding protein (Promega) was also included in the Sequenase extention step, which improved results from $\mathrm{G}+\mathrm{C}$-rich regions. The sequence of each internal primer, of each nested set, is as follows: (1) CCAATTGGACCCTCCCCACACC (position 5272); (2) GGTTCCACCCCAAAACGAGG (253-272); (3) GGCCCTTGTACTATGCGCG $(453-472)$; (4) GCTTGTGTTTAGGCAGCTCAAG (653-674); (5) CCCTGCCTCCTACACGCACG $(847-867) ;(6)$ CCTTGTTCCTAGGGATATC (10711089); (7) GTCTGCCCCACACCCATCC (1266-1284); (8) GGGCACAAAGCTGGCCAGC (1471-1489); and (X1) GGTTCCGACATGGCCGCGTGCG (883-862).

\section{In vivo footprinting using micrococcal nuclease}

Nuclei were prepared from $80 \%$ confluent F9 cells using the method of Shimada et al. (1986). Cells were harvested and resuspended in $\mathrm{R}$ buffer ( $10 \mathrm{mM}$ Tris at $\mathrm{pH} 7.5,10 \mathrm{mM} \mathrm{NaCl}, 3 \mathrm{~mm}$ $\mathrm{MgCl}_{2}, 0.1 \mathrm{~mm}$ PMSF, and $0.25 \mathrm{M}$ sucrose). Cells were lysed by the addition of NP-40 to a final concentration of $0.25 \%$ and gentle homogenization with a Dounce. Nuclei were pelleted through a sucrose cushion (1.1 M sucrose in buffer $\mathrm{R}$ ) twice at $5000 \mathrm{rpm}$ for $3 \mathrm{~min}$ and finally resuspended in $50 \mathrm{mM}$ Tris, $5 \mathrm{mM}$ $\mathrm{MgCl}_{2}, 0.1 \mathrm{~mm}$ EDTA. Glycerol was added to $40 \%$, and the nuclei were frozen at $-70^{\circ} \mathrm{C}$ in aliquots equivalent to $300-500$ $\mu \mathrm{g}$ DNA $/ \mathrm{ml}$. Nuclei $(1 \mathrm{ml}$ aliquot) were pelleted for $5 \mathrm{~min}$ at $5000 \mathrm{rpm}$ in an Eppendorf centrifuge and resuspended in $600 \mu \mathrm{l}$ of buffer M (Shimada et al. 1986; $50 \mathrm{~mm}$ Tris at pH 7.4, $60 \mathrm{~mm}$ $\mathrm{KCl}, 3 \mathrm{mM} \mathrm{CaCl}_{2}$, and $0.34 \mathrm{M}$ sucrose), and $100-\mu \mathrm{l}$ aliquots were digested with increasing amounts $(0.08-2.0$ units $)$ of micrococcal nuclease (Worthington, resuspended at 17 units $/ \mu 1$ in $10 \mathrm{~mm}$ Tris at pH 7.5, 0.5 mM EDTA, 0.5 mM DTT, and 50\% glycerol). Reactions were incubated at $37^{\circ} \mathrm{C}$ for $4 \mathrm{~min}$ and terminated with an equal volume of stop $\operatorname{mix}(1 \%$ SDS, $0.6 \mathrm{M} \mathrm{NaCl}, 20 \mathrm{~mm}$ EDTA, and $20 \mathrm{~mm}$ Tris- $\mathrm{HCl}$ at $\mathrm{pH} 7.5)$. Proteinase $\mathrm{K}$ was added to a final concentration of $100 \mu \mathrm{g} / \mathrm{ml}$, and tubes were incubated at $55^{\circ} \mathrm{C}$ for $1 \mathrm{hr}$ before extracting the DNA using established procedures. Digestion parameters sufficient to produce a nucleosomal ladder were determined empirically. DNA $(3 \mu \mathrm{g})$ was subsequently used for LMPCR amplification (see above), and products were resolved on $2 \%$ agarose gels in TAE buffer $140 \mathrm{mM}$ Tris-acetate, $1 \mathrm{~mm}$ EDTA at $\mathrm{pH} 8$ ). DNA was blotted onto nylon membranes (Hybond $\mathrm{N}+$, Amersham) and hybridized to labeled probe.

\section{In vitro mutagenesis}

An 84-bp DNA oligomer, M1 (Fig. 6A) was used to generate three base pair changes simultaneously in each of the three GC boxes using the method of Kunkel et al. (1987) using a mutagenesis kit (Muta-gene, Bio-Rad). Clones were selected that contained an introduced $X$ hol site and then sequenced using an automatic DNA sequencer $(\mathrm{ABI})$ to check that all of the desired base changes had been made.

\section{Analysis of protein-DNA interactions by} agarose-gel bandshift

A crude protein (NUN) extract was prepared from F9 nuclei (see above) using the method of Lavery and Schibler (1993). Nuclei were pelleted, as described above, from frozen stocks, and nine volumes of NUN buffer (final concentration $0.3 \mathrm{M} \mathrm{NaCl}, 1 \mathrm{M}$ Urea, 1\% NP-40, $25 \mathrm{~mm}$ HEPES at pH 7.6, $1 \mathrm{~mm} \mathrm{DTT}$, and 0.1 mM PMSF) were added. The mixture was vortexed for $5 \mathrm{sec}$ before placing on ice for $15 \mathrm{~min}$. The chromatin precipitate was removed by centrifugation in a microcentrifuge for $10 \mathrm{~min}$ at $10,000 \mathrm{rpm}$ at $4^{\circ} \mathrm{C}$, and glycerol was added to a final concentration of $10 \%$. Aliquots were frozen at $-70^{\circ} \mathrm{C}$, and protein concentration was determined using a Bio-Rad protein assay reagent. Binding reactions were carried out as described by Somma et al. (1991). In a $20 \mu \mathrm{l}$ reaction mixture, $5 \mu \mathrm{g}$ of F9 protein extract was preincubated on ice with $1 \mu \mathrm{g}$ of nonspecific poly[d(I-C)] competitor (in some reactions, $0.1 \mu \mathrm{g}$ of specific competitor was also added) in $25 \mathrm{~mm}$ HEPES, $60 \mathrm{~mm} \mathrm{KCl}, 1 \mathrm{~mm}$ DTT, $0.5 \mathrm{~mm}$ EDTA, and $8.7 \%$ glycerol for $10 \mathrm{~min}$. The radioactive probe was then added and incubation was continued for an additional $30 \mathrm{~min}$ on ice. Restriction fragments from cloned DNA or PCR products were end-labeled with Klenow and ${ }^{32} \mathrm{P}$ labeled nucleotides. Generally, 20-50 pg of probe was used in the binding reaction. The reactions were electrophoresed in $1.5 \%$ agarose gels in $0.5 \times \mathrm{TBE}$ buffer, subsequently dried under vacuum onto DE 81 paper, and exposed to Kodak XAR5 autoradiographic film.

\section{Production of transgenic mice}

Transgenic mice were generated by microinjection of the respective transgene fragment, at a concentration of $1 \mu \mathrm{g} / \mathrm{ml}$ in 10 $\mathrm{mM}$ Tris- $\mathrm{HCl}, 0.1 \mathrm{~mm}$ EDTA $(\mathrm{pH} 7.5)$, using standard procedures (Hogan et al. 1986). Transgenes were injected into single-cell embryos isolated from a cross between $\mathrm{C} 57 \mathrm{Bl} / 6 \times \mathrm{CBA} / \mathrm{Ca} \mathrm{F}_{1}$ mice. Offspring were weaned at 3 weeks of age, and tail biopsies performed for preparation of DNA. This was carried out by incubating the tail tips in proteinase $\mathrm{K}$ buffer $(50 \mathrm{~mm}$ Tris at $\mathrm{pH} 8$, $100 \mathrm{~mm} \mathrm{NaCl}, 100 \mathrm{~mm}$ EDTA, $1 \%$ SDS, and $60 \mu \mathrm{g} / \mathrm{ml}$ of proteinase $\mathrm{K}$ ) overnight at $55^{\circ} \mathrm{C}$, and then extraction of nucleic acids was performed with phenol.

\section{Acknowledgments}

We thank Genevieve Stapleton for her advise on using the LMPCR method, Gillian Brooker, Aileen Greig, and Joan Davidson for their technical support, and Frank Johnson and Graham Brown for their photographic skills. We also thank Sally Cross and Richard Meehan for their helpful comments on the manuscript. This work was supported by The Wellcome Trust, The Imperial Cancer Research Fund, and The Howard Hughes Medical Institute. J.M. was supported by an Agricultural and Food Research Council (AFRC) grant (A550/40).

The publication costs of this article were defrayed in part by payment of page charges. This article must therefore be hereby marked "advertisement" in accordance with 18 USC section 1734 solely to indicate this fact.

\section{Note added in proof}

Brandeis et al. (1994) (Nature, in press) have independently shown the importance of $\mathrm{Spl}$ sites in maintaining the methylation-free status of a CpG island at the hamster aprt gene. 


\section{References}

Antequera, F. and A. Bird. 1993. Number of CpG islands and genes in human and mouse. Proc. Natl. Acad. Sci. 90: 11995-11999

Antequera, F., J. Boyes, and A. Bird. 1990. High levels of de novo methylation and altered chromatin structure at $\mathrm{CpG}$ islands in cell lines. Cell 62: 503-514.

Bird, A.P. 1986. CpG-rich islands and the function of DNA methylation. Nature 321: 209-213.

1987. CpG islands as gene markers in the vertebrate nucleus. Trends Genet. 3: 342-347.

Bird, A., M. Taggart, M. Frommer, O.J. Miller, and D. Macleod. 1985. A fraction of the mouse genome that is derived from islands of non-methylated, CpG-rich DNA. Cell 40: 91-99.

Bird, A.P., M.H. Taggart, R.D. Nicholls, and D.R. Higgs. 1987. Non-methylated CpG-rich islands at the human alphaglobin locus: Implications for evolution of the alpha-globin pseudogene. EMBO 1. 6: 999-1004.

Brandeis, M., T. Kafri, M. Ariel, J.R. Chaillet, J. McCarrey, A. Razin, and H. Cedar. 1993. The ontogeny of allele-specific methylation associated with imprinted genes in the mouse. $E M B O$ J. 12: 3669-3677.

Carotti, D., F. Palitti, P. Lavia, and R. Strom. 1989. In vitro methylation of CpG-rich islands. Nucleic Acids Res. 17: 9219-9229.

Choi, Y.-C. and C.-B. Chae. 1991. DNA hypomethylation and germ cell-specific expression of testis-specific $\mathrm{H} 2 \mathrm{~B}$ histone gene. J. Biol. Chem. 266: 20504-20511.

- 1993. Demethylation of somatic and testis-specific histone $\mathrm{H} 2 \mathrm{~A}$ and $\mathrm{H} 2 \mathrm{~B}$ genes in $\mathrm{F} 9$ embryonal carcinoma cells. Mol. Cell. Biol. 13: 5538-5548.

Cooper, D.N., M.H. Taggart, and A.P. Bird. 1983. Unmethylated domains in vertebrate DNA. Nucleic Acids Res. 11: 647658.

Driscoll, D.J. and B.R. Migeon. 1990. Sex difference in methylation of single-copy genes in human meiotic germ cells: Implications for $\mathrm{X}$ chromosome inactivation, parental imprinting, and origin of CpG mutations. Somatic Cell Mol. Genet. 16: $267-282$.

Dush, M.K., J.M. Sikela, S.A. Khan, J.A. Tischfield, and P.J. Stambrook. 1985. Nucleotide sequence and organization of the mouse adenine phosphoribosyltransferase gene: Presence of a coding region common to animal and bacterial phosphpribosyltransferases that has a variable intron/exon arrangement. Proc. Nat1. Acad. Sci. 82: 2731-2735.

Dush, M.K., M.R. Briggs, M.E. Royce, D.A. Schaff, S.A. Khan, J.A. Tischfield, and P.J. Stambrook. 1988. Identification of DNA sequences required for mouse APRT gene expression. Nucleic Acids Res. 16: 8509-8525.

Ferguson-Smith, A.C., H. Sasaki, B.M. Cattanach, and M.A. Surani. 1993. Parental-origin-specific epigenetic modification of the mouse H19 gene. Nature 362: 751-755.

Frank, D., I. Keshet, M. Shani, A. Levine, A. Razin, and H. Cedar. 1991. Demethylation of CpG islands in embryonic cells. Nature 351: 239-241.

Frommer, M., L.E. McDonald, D.S. Millar, C.M. Collis, J. Watt, G.W. Grigg, P.L. Molloy, and C.L. Paul. 1992. A genomic sequencing protocol that yields a positive display of 5-methylcytosine residues in individual DNA strands. Proc. Natl. Acad. Sci. 89: 1827-1831.

Gardiner-Garden, M. and M. Frommer. 1987. CpG islands in vertebrate genomes. I. Mol. Biol. 196: 261-282.

Gunderson, G., A.-B. Kolsto, and H. Prydz. 1991. Differential methylation of a CpG-island concatemer in hemi- and homozygous transgenic mice. FEBS Lett. 295: 214-218.
Hogan, B., F. Constantini, and E. Lacy. 1986. Manipulating the mouse embryo. Cold Spring Harbor Laboratory, Cold Spring Harbor, New York.

Höller, M., G. Westin, J. Jiricny, and W. Shaffner. 1988. Sp1 transcription factor binds DNA and activates transcription even when the binding site is CpG methylated. Genes \& Dev. 2: 1127-1135.

Holliday, R. and J.E. Pugh. 1975. DNA modification mechanisms and gene activity during development. Science 186: $226-232$.

Jones, P.A., M.J. Wolkowitz, W.M.I. Rideout, F.A. Gonzales, C.M. Marziasz, G.A. Coetzee, and S.J. Tapscott. 1990. De novo methylation of the MyoD1 CpG island during the establishment of immortal cell lines. Proc. Natl. Acad. Sci. 87: 6117-6121.

Kadonaga, J., K. Jones, and R. Tjian. 1986. Promoter-specific activation of RNA polymerase II transcription by Spl. Trends Biochem. Sci. 11: 20-23.

Kolsto, A.-B., G. Kollias, V. Giguere, K.-I. Isobe, H. Prydz, and F. Grosveld. 1986. The maintenance of methylation-free islands in transgenic mice. Nucleic Acids Res. 14: 9667-9678.

Kunkel, T.A., I.D. Roberts, and R.A. Zakour. 1987. Rapid and efficient site-specific mutagenesis without phenotypic selection. Methods Enzymol. 154: 367-382.

Lavery, D.J. and U. Schibler. 1993. Circadian transcription of the cholesterol $7 \alpha$ hydroxylase gene may involve the liverenriched bZIP protein DBP. Genes \& Dev. 7: 1871-1884.

Mehtali, M., M. LeMeur, and R. Lathe. 1990. The methylationfree status of a housekeeping transgene is lost at high copy number. Gene 91: 179-184.

Mueller, P.J. and B. Wold. 1989. In vivo footprinting of a muscle specific enhancer by ligation mediated PCR. Science 246: 780-786.

Mummaneni, P., P.L. Bishop, and M.S. Turker. 1993. A cisacting element accounts for a conserved methylation pattern upstream of the mouse adenine phosphoribosyltransferase gene. J. Biol. Chem. 268: 552-558.

Pfeifer, G.P. and A.D. Riggs. 1991. Chromatin differences between active and inactive $\mathrm{X}$ chromosomes revealed by genomic footprinting of permeabilized cells using DNase I and ligation-mediated PCR. Genes \& Dev. 5: 1102-1113.

Pfeifer, G.P., S.D. Steigerwald, P.R. Mueller, B. Wold, and A.D. Riggs. 1989. Genomic sequencing and methylation analysis by ligation mediated PCR. Science 246: 810-813.

Pfeifer, G.P., R.L. Tanguay, S.D. Steigerwald, and A.D. Riggs. 1990. In vivo footprint and methylation analysis by PCRaided genomic sequencing: Comparison of active and inactive X chromosomal DNA at the CpG island and promoter of human Pgk-1. Genes \& Dev. 4: 1277-1287.

Ponce, M.R. and J.L. Micol. 1992. PCR amplification of long DNA fragments. Nucleic Acids Res. 20: 623.

Riggs, A.D. 1975. X-inactivation, differentiation and DNA methylation. Cytogenet. Cell. Genet. 14: 9-25.

Riggs, A.D. and G.P. Pfeifer. 1992. X-chromosome inactivation and cell memory. Trends Genet. 8: 169-174.

Shimada, T., K. Inokuchi, and A.W. Nienhuis. 1986. Chromatin structure of the human dihydrofolate reductase gene promoter. I. Biol. Chem. 261: 1445-1452.

Somma, M.P., I. Gambino, and P. Lavia. 1991. Transcription factors binding to the mouse HTF9 housekeeping promoter differ between cell types. Nucleic Acids Res. 19: 4451-4458.

Spanopoulou, E., V. Giguere, and F. Grosveld. 1991. The functional domains of the Thy-1 gene promoter. Mol. Cell. Biol. 11: 2216-2228.

Stapleton, G., M.P. Somma, and P. Lavia. 1993. Cell type-specific interactions of transcription factors with a housekeep- 


\section{Macleod et al.}

ing promoter in vivo. Nucleic Acids Res. 21: 2465-2471.

Stöger, R., P. Kubicka, C.-G. Liu, T. Kafri, A. Razin, H. Cedar, and D.P. Barlow. 1993. Maternal specific methylation of the imprinted mouse Igf2r locus identifies the expressed locus as carrying the imprinting signal. Cell 73: 61-71.

Szyf, M., G. Tanigawa, and P.L.J. McCarthy. 1990. A DNA signal from the thy-1 gene defines de novo methylation patterns in embryonic stem cells. Mol. Cell. Biol. 10: 43964400.

Tazi, J. and A. Bird. 1990. Alternative chromatin structure at CpG islands. 1990. Cell 60: 909-920.

Tykocinski, M.L. and E.C. Max. 1984. CG clusters in MHC genes and 5' demethylated genes. Nucleic Acids Res. 12: 4385-4396.

Turker, M.S., K. Swisshelm, A.C. Smith, and G.M. Martin. 1989. A partial methylation profile for a CpG site is stably maintained in mammalian tissues and cultured cell lines. I. Biol. Chem. 264: 11632-11636.

Turker, M.S., P. Mummaneni, and P.L. Bishop. 1991. Regionand cell type-specific de novo DNA methylation in cultured mammalian cells. Somatic Cell Mol. Genet. 17: 151-157.

Yagi, M. and M. Groudine. 1986. Chromatin structure and developmental expression of the human alpha-globin cluster. Mol. Cell. Biol. 6: 1108-1116. 


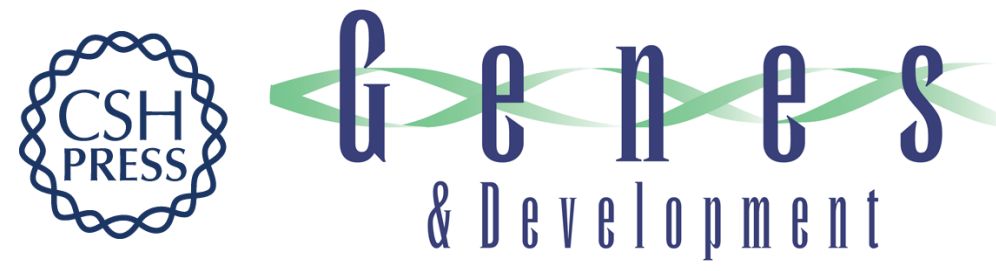

\section{Sp1 sites in the mouse aprt gene promoter are required to prevent methylation of the $\mathrm{CpG}$ island.}

D Macleod, J Charlton, J Mullins, et al.

Genes Dev. 1994, 8:

Access the most recent version at doi:10.1101/gad.8.19.2282

References This article cites 46 articles, 18 of which can be accessed free at:

http://genesdev.cshlp.org/content/8/19/2282.full.html\#ref-list-1

License

Email Alerting

Service

Receive free email alerts when new articles cite this article - sign up in the box at the top right corner of the article or click here.

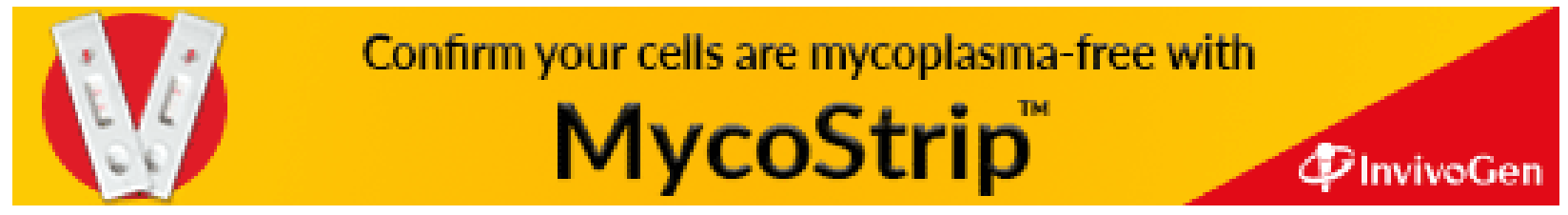

